\title{
A pilot study to evaluate the diagnostic accuracy of local terminology for malaria screening among children in rural Malawi
}

\section{Thomas Bisika}

University of Pretoria - Health Sciences, Pretoria, South Africa Correspondence: Dr. T Bisika email: thomas.bisika@up.ac.za

\section{Abstract \\ Background}

Malaria is a serious health problem in Malawi. It is responsible for $43 \%$ of all out patient visits and $19 \%$ of all deaths occurring to children under five years of age. Rapid diagnosis and appropriate treatment can avert most malaria deaths. However this is not always possible in resource limited settings where functioning laboratories are almost nonexistent.

\section{Methods}

This paper assesses the accuracy of local terminology in detecting parasitemia in children using blood smears as the reference standard.

\section{Results}

The study observes that there are local terms that can be used as an inexpensive, readily available and easily implementable malaria screening test in Malawian children in rural areas. These terms include "malungo" (official name for malaria), "kutentha thupi" (hot body), "kutsegula m'mimba" (official term for diarrhoea) and "kukhosomola" (coughing). The local terms "malungo" and "kutentha thupi" yielded better results.

\section{Conclusion}

Although the local terminology produced results that are less than optimal, the study concludes that the knowledge of sensitivity and specificity of local terminology can be used by local healthcare practitioners to identify children who could benefit from malaria confirmation testing and presumptive treatment. The study, however, cautions that these terms should be used as an entry point to malaria case management as they do not distinguish the severity of the malaria infection and all of them produced a sensitivity of less than $50 \%$.

\section{Introduction}

Malaria is a serious health problem in Malawi that accounts for $19 \%$ of all deaths occurring to children under five years of age ${ }^{1}$. Rapid identification of malaria can avert most deaths. However malaria symptoms are nonspecific and can be confused with other illness such as pneumonia, respiratory tract infections, gastroenteritis and tuberculosis ${ }^{2}$ . Blood smears are the gold standard for malaria diagnosis in Malawi, but these are usually nonexistent in rural areas which are statistically associated with failure to receive prompt appropriate malaria treatment ${ }^{3}$. This is an area of concern because malaria control in Africa relies primarily on the early treatment of clinical disease ${ }^{4}$. Against this background health care workers rely on case history which is often provided by mothers who serve as proxy respondents for their children ${ }^{5}$. The patient-health care provider interaction in rural Malawi generally entails patient description of symptoms using local terminology. These local terminologies are used by health practitioners to decide on the course of action to follow in children with possible malaria. Hitherto, there has been no study that has assessed the diagnostic accuracy of local terminology for screening malaria parasitemia. The purpose of this study was, therefore, to evaluate the diagnostic accuracy of local terminology for screening malaria parasitemia among children in rural Malawi.

\section{Methods}

\section{Participants}

The epidemiologic survey was conducted in the Zomba District of southern Malawi in 1996 in a small community called Namasalima as part of a rapid ethnographic study of malaria case management in children. This area was specifically selected because widespread irrigation rice farming and the lack of malaria control programs contribute to endemic malaria. The study population included children under 5 who were ill at the time of the survey. Mothers and care providers were asked to bring the sick children to 2 mobile clinics. The sample size was calculated based on the malaria prevalence in Zomba District and was calculated using the formula given below ${ }^{6,7}$ :

Sample size $=\left\{Z 2(1-\alpha) *\left(p^{*}(1-p)\right\} /\right.$ c 2

Where:

$\mathrm{Z}=\mathrm{Z}$ value (e.g. 1.96 for $95 \%$ confidence level that is $\alpha=0.05)$

$\mathrm{p}=$ malaria prevalence, expressed as decimal

$c=$ confidence interval width, expressed as decimal

A total of 40 children were thus included in the sample. Only children whose mothers or care providers gave informed consent and used local terminology that was associates with febrile illness in an ongoing ethnographic study of malaria case management in rural Malawi ${ }^{8}$ were included in the study. This number was reached after 158 iterations and the cases were picked consecutively. All children diagnosed with malaria were treated using the existing national treatment guidelines. The study protocol was approved by the National Health Sciences Research Committee of the Malawi government (Reference\# Malawi/Gov/05/5G).

\section{Test Methods}

\section{Reference Standard}

A registered nurse and laboratory assistant collected blood samples from participating children using finger prick. The samples were tested for malaria parasites using the gold standard blood smear microscopy by a senior laboratory technician at the Zomba Central Hospital. Giemsa-stained thick smears were analysed using high power oil objective field 9 .

\section{Index Test}

Mothers were initially asked to describe their child's illness using local terminology. The terms used included "malungo" 
which coincidentally is the official local term for malaria in Malawi, "Kutsegula m'mimba" which literally means "opening of the stomach" and in biomedical terms this is called diarrhoea, "kutsokomola" or "kukhosomola" which literally means "coughing", and "Kutentha thupi" which literally means "hot body". The last term was mostly used to refer to fever.

\section{Statistical Analysis}

Sensitivity, specificity, positive predictive value and negative predictive value with corresponding $95 \%$ confidence intervals were estimated for each local term using OpenEpi version 2.2.1, an open source software program for epidemiologic statistics $^{10}$.

\section{Results}

\section{Demographic characteristics}

Most of the sick children were between 0 and 2 years old. More than half of the children were male and just over three quarters of them were brought by their mothers (Table 1). The excess number of males in the sample could be due to the fact that most of the children were age 0 which means that the initial sex ratio at birth which is usually about 105 males per 100 females may have played a part. Overall 64\% of the children who participated in the survey had parasitemia.

Table 1 Demographic characteristics $(N=40)$

\begin{tabular}{|l|l|l|}
\hline Characteristic & Count (\%) & $\begin{array}{l}\text { Parasitemia present } \\
\text { Count (\%) }\end{array}$ \\
\hline Age & & \\
\hline 0 & $13(32.5)$ & $9(69.2)$ \\
\hline 1 & $12(30.0)$ & $7(58.3)$ \\
\hline 2 & $7(17.5)$ & $3(42.9)$ \\
\hline 3 & $5(12.5)$ & $4(80.0)$ \\
\hline 4 & $3(7.5)$ & $1(33.3)$ \\
\hline & & \\
\hline Sex & & \\
\hline Female & $17(42.5)$ & $8(47.1)$ \\
\hline Male & $23(57.5)$ & $16(69.6)$ \\
\hline & & \\
\hline Person accompanying child & & \\
\hline Mother & $31(77.5)$ & $21(67.7)$ \\
\hline Father & $3(7.5)$ & $1(33.3)$ \\
\hline Other & $6(15.0)$ & $2(33.3)$ \\
\hline
\end{tabular}

\section{Diagnostic Accuracy}

A total of 40 children were screened for malaria based on local terminology used by the mothers when they presented at a mobile clinic with a sick child. Table 2 summarizes the sensitivity, specificity, positive predictive value and negative predictive value of local terminology using blood smears as the reference standard. The term "malungo" had the highest sensitivity $(41.67 \%, 95 \% \mathrm{CI}=24.47,61.17)$ and specificity $(93.75 \%, 95 \% \mathrm{CI}=71.67,98.89)$ of all the local terms. "Kutentha thupi" yielded sensitivity of $20.83 \%$ (95\% $\mathrm{CI}=9.25,40.47)$ and specificity of $68.75 \%(95 \% \mathrm{CI}=44.4$, 85.84). On the other hand, "Kukhosola" had a sensitivity of $16.67 \%(95 \% \mathrm{CI}=6.68,35.85)$ and specificity of $81.25 \%$ $(95 \%$ CI $=56.99,93.41)$ while "Kutsegula m'mimba" had a sensitivity of $8.33 \%(95 \% \mathrm{CI}=2.32,25.85)$ and specificity of $87.5 \%(95 \% \mathrm{CI}=63.98,96.5)$.

Table 2 Diagnostic accuracy of local terminology for malatia screening

\begin{tabular}{|c|c|c|c|}
\hline Terminology & Parameter & Estimate & $(95 \% \mathrm{Cl})$ \\
\hline \multicolumn{4}{|l|}{ Malungo } \\
\hline & Sensitivity & $41.67 \%$ & $(24.47,61.17)$ \\
\hline & Specificity & $93.75 \%$ & $(71.67,98.89)$ \\
\hline & $\begin{array}{l}\text { Positive } \\
\text { Predictive Value }\end{array}$ & $90.91 \%$ & $(62.26,98.38)$ \\
\hline & $\begin{array}{l}\text { Negative } \\
\text { Predictive Value }\end{array}$ & $51.72 \%$ & $(34.43,68.61)$ \\
\hline \multicolumn{4}{|l|}{ Kutentha thupi } \\
\hline & Sensitivity & $20.83 \%$ & $(9.245,40.47)$ \\
\hline & Specificity & $68.75 \%$ & $(44.4,85.84)$ \\
\hline & $\begin{array}{l}\text { Positive } \\
\text { Predictive Value }\end{array}$ & $50 \%$ & $(23.66,76.34)$ \\
\hline & $\begin{array}{l}\text { Negative } \\
\text { Predictive Value }\end{array}$ & $36.67 \%$ & $(21.87,54.49)$ \\
\hline \multicolumn{4}{|l|}{ Kukhosomola } \\
\hline & Sensitivity & $16.67 \%$ & $(6.679,35.85)$ \\
\hline & Specificity & $81.25 \%$ & $(56.99,93.41)$ \\
\hline & $\begin{array}{l}\text { Positive } \\
\text { Predictive Value }\end{array}$ & $57.14 \%$ & $(25.05,84.18)$ \\
\hline & $\begin{array}{l}\text { Negative } \\
\text { Predictive Value }\end{array}$ & $39.39 \%$ & $(24.68,56.32)$ \\
\hline \multicolumn{4}{|l|}{$\begin{array}{l}\text { Kutsegula } \\
\text { m'mimba }\end{array}$} \\
\hline & Sensitivity & $8.333 \%$ & $(2.316,25.85)$ \\
\hline & Specificity & $87.5 \%$ & $(63.98,96.5)$ \\
\hline & $\begin{array}{l}\text { Positive } \\
\text { Predictive Value }\end{array}$ & $50 \%$ & $(15,85)$ \\
\hline & $\begin{array}{l}\text { Negative } \\
\text { Predictive Value }\end{array}$ & $38.89 \%$ & $(24.78,55.14)$ \\
\hline
\end{tabular}

\section{Discussion}

The results indicate that local terminology could have potential in malaria screening in rural areas. If these findings can be replicated in a much larger study a policy to use local terminology in malaria screening can be justified. This will promote access to simple and effective malaria interventions like home management of uncomplicated malaria by the rural poor $^{11}$. In our case all the local terms resulted in a sensitivity of less that $50 \%$ which means that more than half of the children under age 5 with malaria may go undetected.

Commercial rapid diagnostic tests have better sensitivity and specificity. For example, the overall sensitivity obtained with the OptiMAL test for $P$. falciparum and $P$. vivax was 94 and $88 \%$, respectively, with a specificity of 100 and $99 \%$, respectively ${ }^{12}$. The sensitivity of Acridine orange (AO) staining for detection of malaria parasites in infections with parasite levels of $<100$ parasites $/ \mu \mathrm{l}(0.002 \%$ parasitemia) has 
been reported to range from 41 to $93 \%{ }^{13}$. The specificity for infections with $P$. falciparum is, however, excellent $(>93 \%)^{14}$, with most observers recognizing the small ring forms ${ }^{15}$. Performance of the assessment of these rapid diagnostic tests in resource-limited areas with high prevalence of malaria would help in the evaluation of screening accuracy as well as usefulness of local terminology in malaria screening.

This pilot study has several limitations. Foremost, the small sample size precludes definitive conclusions regarding the utility of local terminology for screening malaria among children under the age of 5 years in rural Malawi. Furthermore, $17.5 \%(7 / 40)$ of mothers were unable to convey their children's symptoms, of whom $43 \%$ (3/7) were diagnosed with malaria. It must, however, be acknowledged that the lack of a malaria control program in the study area may have contributed to the mothers being unaware of common symptoms. Areas with malaria control programs and widespread knowledge of the symptoms may affect the diagnostic accuracy of the terms. However, these areas are more likely to have lower prevalence of malaria, which could also affect the diagnostic accuracy .

The results of this pilot study indicate that local terms for describing symptoms may be useful to local healthcare practitioners for identifying children who could benefit from malaria confirmation testing and presumptive treatment in this resource-limited area. The local terms "malungo" and "kutentha thupi" yielded a sensitivity and specificity comparable to diagnostic tests such as Acridine orange (AO) and antigen detection tests such as ICT and OptiMAL. However, the potential utility of local terminology for screening malaria among children in rural Malawi should be evaluated in a larger study. Such a study will have to pay particular attention to how different dialects existing in the same community may affect the performance of the index. Similarly, there is need to investigate other diseases that could have caused fever in children who had no confirmed diagnosis of malaria as well as those who had confirmed parasitemia as there could be cases of concurrent infection. This is crucial because the fact that somebody has malaria parasitaemia does not mean that the fever is due to the parasitaemia.

\section{Acknowledgement}

The author would like to thank Dr Patricia Huddelson of the World Health Organization Special Programme for Research and Training in Tropical Diseases for her guidance and advice and Dr James Mwenechanya, District Health Officer for Zomba, Sharon Bisika, pediatric nurse at Domasi Rural Hospital, and Mr M. Chisiye a Chief Laboratory Technician at Zomba Central Hospital who arranged the mobile clinics and supervised the collection and analysis of blood smears.

\section{Funding}

This study was funded by the World Health Organization Special Programme for Research and Training in Tropical Diseases as part of the field test for the Guidelines for Conducting Rapid Ethnographic Studies for Malaria Case Management in Children (Project ID: 950658).

\section{References}

1. Macro International Inc . Malawi Demographic and Health Survey. 2000

2. Nwanyanwu OC. Kumwenda N, Jemu S, Ziba C, Kazembe, PN, Redd SC. Malaria and HIV infection among sugar estate workers in Malawi. 1994; Centers for Disease Control, Atlanta.

3. Holtz TH, Kachur SP, Marum LH, Mkandala C, Chizani N, Roberts JM, Macheso A and Parise EM. 2003. Care seeking behaviour and treatment of febrile illness in children aged less than five years: a household survey in Blantyre District, Malawi. Transactions of the Royal Society of Tropical Medicine and Hygiene 97(5): 491-497

4. Marsh VM, Mutemi WM, Muturi J, Haaland A, Watkins WM, Otieno $G$ and K Marsh. 1999. Changing home treatment of childhood fevers by training shop keepers in rural Kenya. Tropical Medicine and International Health 4(5): 383-389

5. Nwanyanwu OC, Redd SC, Ziba C, Luby SP, Mount DL, Franco C, Nyasulu Y and Chitsulo L. 1996. Validity of mother's history regarding antimalarial drug use in Malawian children under five years old. Transactions of the Royal Society of Tropical Medicine and Hygiene 90, 66-68

6. Midhet F, Becker S and Berendes HW. 1998. Contextual Determinants of Maternal Mortality in Rural Pakistan. Soc. Sci Med, 46(12): $1587-$ 1598

7. Bonita R, Beaglehole R and Kjellström T. 2006. Basic Epidemilogy. India: World Health Organization

8. Bisika T. 1996. An ethnographic study of malaria case management in rural Malawi. Geneva, WHO/TDR

9. Laoboonchai, A, Kawamoto, F, Thanoosingha, N, Kojima, S, Scott Miller, RR, Kain, KC, Wongsrichanalai, C. 2001.PCR-based ELISA technique for malaria diagnosis of specimens from Thailand. Tropical Medicine \& International Health:Volume 6(6): 458-462

10. OpenEpi version 2.2.1 online resource which can be found on the following URL: http://www.openepi.com/Menu/OpenEpiMenu. htm accessed on February 13, 2009.

11. WHO/TDR. 2007. Ten Year Vision and Strategy. Geneva: WHO/ TDR

12. Palmer, C. J., J. F. Lindo, W. I. Klaskala, J. A. Quesada, R. Kaminsky, M. K. Baum, and A. L. Ager. 1998. Evaluation of the OptiMAL test for rapid diagnosis Plasmodium vivax and Plasmodium falciparum malaria. J. Clin. Microbiol. 36:203-206.

13. Wongsrichanalai, C., J. Pornsilapatip, V. Namsiriponpun, H. K. Webster, A. Luccini, P. Pansamdang, H. Wilde, and M. Prasittisuk. 1991. Acridine orange fluorescent microscopy and the detection of malaria in populations with low-density parasitemia. Am. J. Trop. Med. Hyg. 44:17-20.

14. Gaye, O., M. Diouf, and S. Diallo. 1999. A comparison of thick films, QBC malaria, PCR and PATH falciparum malaria test strip in Plasmodium falciparum diagnosis. Parasite 6:273-275.

15. Anthony Moody. 2002. Rapid Diagnostic Tests for Malaria Parasites. Clinical Microbiology Reviews, January 2002, p. 66-78, Vol. 15,No. 1

16. Leeflang MM, Bossuyt PM, Irwig L. Diagnostic test accuracy may vary with prevalence: implications for evidence-based diagnosis. J Clin Epidemiol. 2009 Jan;62(1):5-12. 